Chelton, E. T. J. \& Jones, A. S. (1959). J. gen. Microbiol. 21, 652-657

\title{
The Gram-Staining Reaction of Disintegrated Micro-organisms
}

\author{
By E. T. J. CHELTON AND A. S. JONES \\ Chemistry Department, The University, Edgbaston, Birmingham 15
}

SUMMARY: Disintegration of yeast and Clostridium welchii gave cell envelopes which stained Gram-negative by a modified Jensen's Gram-staining procedure (procedure 1), but stained in part Gram-positive by a modification of the Gram stain in which the films were dried after application of the iodine and before application of the decolorizing agent $(90 \% \mathrm{v} / \mathrm{v}$ ethanol; procedure 2$)$. Procedure 2 appeared to give a typical Gram reaction in that a series of organisms gave identical results when stained by the two procedures. Disintegrated Gram-negative organisms gave only Gram-negative material when stained by procedure 2. The Gram-positive material could be removed from the yeast envelopes by extraction at $\mathrm{pH} 8$, but attempts to 'replate' the envelopes with the extract were unsuccessful. The results suggest that the Gram-staining reaction of yeast and $C$. relchii is due in part to a specific staining component and in part to a factor dependent upon the intact nature of the cells. The latter may be associated with the stability or orientation of the staining component or with some membrane effect.

A number of workers have noted that when Gram-positive organisms are broken they become Gram-negative (Benians, 1912, 1919; Burke \& Barnes, 1929). These results have been taken as support for the theory that the Gram-staining reaction is due to the presence of a membrane in Grampositive organisms which is impermeable either to the dye +iodine complex or to the decolorizing agent. This effect of breaking cells may be equally well explained as being due to the degradation or disaggregation of a Gram-positive complex when the cell membrane is ruptured. It is not certain that Grampositive organisms always become Gram-negative when broken. Thus Burke \& Barnes (1929) observed certain Gram-positive structures in preparations of broken yeast cells, and Kemp (1931) showed that broken yeast cells showed Gram-positive structures when stained by a particular modification of the Gram stain.

The results reported in the present paper show that although certain Grampositive organisms which had been disintegrated by shaking with glass balls stained Gram-negative by Jensen's modification of the Gram method, a change in this procedure as simple as just allowing the slide to dry before applying the decolorizing agent resulted in the distintegrated organism staining Grampositive.

\section{METHODS}

Organisms. The following were used: Saccharomyces cerevisiae (baker's yeast, Distillers Co., Ltd. DCL); Clostridium welchii; Sarcina lutea; Escherichia coli; Azotobacter chröococcum (NCIB 8003); Caryophanon sp. (kindly supplied by Dr T. Gibson). S. lutea, C. welchii and $E$. coli were grown at $37^{\circ}$ in a Lemco 
broth medium, Azotobacter chrö̈coccum on mannitol agar at $25^{\circ}$ and Caryophanon sp. on yeast-extract agar at $25^{\circ}$.

Disintegration of the organisms. A suspension of organisms in distilled water ( 5 ml.) was shaken with ballotini glass balls (no. $5 ; 3$ g.) in a Mickle shaker (Mickle, 1948). Agitation was carried out at full amplitude for periods of $1 \mathrm{~min}$. followed by $1 \mathrm{~min}$. periods at rest, in order to avoid excessive heating. Optimum breakage was found by microscopical examination. The time required varied from $3 \mathrm{~min}$. breaking time for Caryophanon sp. to 5-10 min. for baker's yeast.

\section{Techniques used for the Gram-staining method}

A small loopful of the fluid containing material to be stained was spread thinly on the slide, allowed to dry in air and then fixed by passing the slide through a Bunsen flame. The reagents used were: aqueous solution of methyl violet 6B (British Drug Houses Ltd.; 0.5\%, w/v); Lugol's iodine solution; $90 \%$ ethanol (ethanol + water, $9+1, v / v)$; dilute carbol-fuchsin ( 1 in 20 dilution of Ziehl-Neelsen stain).

The film was covered with methyl violet solution which was allowed to act for $2 \mathrm{~min}$. The stain was then poured off and, with the slide held at an angle, the iodine solution was applied so that it washed the slide. The iodine solution was allowed to act for 2 min., then poured off and $90 \%$ ethanol applied for $2 \mathrm{~min}$. The $90 \%$ ethanol was poured off, dilute carbol-fuchsin applied for 15 sec., the slide washed with water and dried. Except for times of application this method approximates to Jensen's modification of the Gram stain and will be referred to as procedure 1 .

It was found with disintegrated organisms that different results were obtained when, after treatment with the iodine solution and before decolorization with $90 \%$ ethanol, the slide was dried either by blotting or by allowing to stand in air for a few minutes. This modified method will be known as procedure 2. The best known Gram-staining procedure in which the slide is blotted dry after application of the iodine is that of Hucker (1922). This procedure is recommended by the Society of American Bacteriologists; Burke (1922) recommends blotting but not drying the slide before application of the decolorizing agent. Hucker's procedure was not used in the present work because the short time for the application of the decolorizing agent was not sufficient to remove the dye + iodine complex from the cell debris present in films of disintegrated organisms.

\section{RESULTS}

Baker's yeast was disintegrated in the Mickle shaker as previously described and at intervals films prepared and stained by Gram's method. Staining by procedure 1 showed only Gram-negative debris and unstained cell envelopes (Pl. 1, fig. 1), but staining by procedure 2 (Pl. 1, fig. 2) showed, in addition to light purple-staining debris, Gram-positive material, most of which adhered to the cell envelopes. The experiments were also carried out with Clostridium 
welchii; preparations stained by procedure 2 (Pl. 1, fig. 3) showed Grampositive areas. Experiments with Sarcina lutea were less conclusive but preparations of disintegrated organisms stained by procedure 2 showed considerably more purple staining than those stained by procedure 1 .

In order to eliminate the possibility that the staining was due to artifacts produced by the disintegration of the organisms, the Gram-negative organisms Escherichia coli, Azotobacter chroöcoccum and Caryophanon sp. were disintegrated and stained by procedures 1 and 2. No Gram-positive material was observed.

The possibility that procedure 2 did not give a typical Gram reaction and was capable of giving false positive results was excluded by the fact that procedures 1 and 2 gave identical results when tested on a large number of intact organisms. Thus the following organisms stained Gram-positive by both procedures: Bacillus megaterium, B. subtilis, Clostridium welchii; Diplococcus crassus, Saccharomyces cerevisiae, Sarcina lutea, Streptococcus faecalis; and the following organisms stained Gram negative: Azotobacter chroöcoccum, Bacillus brevis, Caryophanon sp. Chromobacterium prodigiosum (Serratia marcescens), Cloaca cloacae, Escherichia coli, Klebsiella aerogenes, K. pneumoniae, Neisseria catarrhalis.

\section{The effect of ethanol concentration on the Gram reaction}

Since the different results obtained by the two staining procedures must have been due to the presence of water on the slide in procedure 1 , the effect of varying the water content of the decolorizing agent on the staining of disintegrated yeast by procedure 2 was investigated. The condition which gave results most similar to those obtained by procedure 1 was with $70 \%$ ethanol (ethanol + water, $7+3 ; \mathrm{v} / \mathrm{v}$ ), but even in this case there was a slight retention of the purple dye by the cell debris. At lower concentrations of ethanol the debris retained the purple dye and at higher ethanol concentrations the appearance was similar to that obtained with $90 \%$ ethanol. When films of disintegrated yeast were dried after application of the iodine, then re-wetted with water for $2 \mathrm{~min}$. before application of the $90 \%$ ethanol, the films finally obtained were similar to those in which $70 \%$ ethanol was used as the decolorizing agent.

\section{Reversed Gram staining}

Attempts were made to stain organisms with an ethanolic solution of the methyl violet+iodine complex. Gram-positive organisms would not be expected to take up the stain if, as has been suggested, they have a cell membrane which is impermeable to the complex. The concentration of methyl violet in a saturated solution of the complex in ethanol was only $0.015 \%$ compared with the $0.5 \%$ for the aqueous solutions used for the normal Gramstaining procedure. Therefore in the former case very poor staining was obtained which could only be detected by macroscopic examination of large films $\left(c .300 \mathrm{~cm} .{ }^{2}\right)$. The technique was to apply the ethanolic solution of the methyl violet + iodine complex to the films for 2 min., remove, dry and wash 


\section{Gram staining of disintegrated organisms}

with absolute ethanol. When the methyl violet +iodine complex was applied in $90 \%$ ethanol, baker's yeast, Sarcina lutea and Escherichia coli were stained purple, indicating that the dye had penetrated the organisms. It was unlikely that the dye had been only adsorbed on the outer surface of the organisms because the dye could not be removed by washing with absolute ethanol in which the dye + iodine complex is easily soluble, and yeast would not take up dye from a solution of the complex in absolute ethanol. Although the intensity of staining with the $90 \%$ ethanolic solution of the complex was much less than in the direct Gram-staining procedure, this might have been because of the lower concentration of methyl violet which had to be used in the reversed procedure. When yeast was stained with aqueous $0.015 \%$ methyl violet the amount of stain taken up corresponded closely with that taken up from the $90 \%$ ethanolic solution of the methyl violet + iodine complex.

\section{The preparation of Gram-positive cell envelopes from baker's yeast}

A suspension of baker's yeast (2. $\mathrm{g}$. fresh pressed DCL yeast in $5 \mathrm{ml}$. distilled water) was mixed with $3 \mathrm{~g}$. no. 5 .ballotini glass balls. The cells were disintegrated as previously described but with cooling in ice water for 2 min. between each $1 \mathrm{~min}$. treatment in the Mickle shaker. When the cells were almost completely broken (5-10 min. breaking time) but the envelopes not destroyed, the suspension ( $\mathrm{pH} 5$ ) was removed from the glass balls, diluted with an equal volume of ice-cold distilled water and centrifuged at $700 \mathrm{~g}$ in an M.S.E. Minor centrifuge for $5 \mathrm{~min}$. Three layers were observed: an upper layer of liquid, a white middle layer of cell envelopes and a bottom layer consisting mainly of unbroken cells. The middle white layer was separated and washed twice with ice-cold distilled water. This contained cell envelopes which stained Gram positive by procedure 2 (Pl. 1, fig. 4) and was almost free from amorphous debris.

\section{The preparation of Gram-negative yeast cell envelopes}

The Gram-positive cell envelopes were suspended in distilled water (c. $10 \mathrm{ml}$.) which had been adjusted to $\mathrm{pH} 8$ with dilute sodium hydroxide. After standing at room temperature for $5 \mathrm{~min}$. the suspension was centrifuged for $3 \mathrm{~min}$. on an M.S.E. Minor centrifuge at $700 \mathrm{~g}$. The sediment was re-suspended in distilled water ( $\mathrm{pH} 8,10 \mathrm{ml}$.), centrifuged at $700 \mathrm{~g}$ after $5 \mathrm{~min}$. standing at room temperature and the sediment suspended in distilled water. The cell envelopes in this preparation stained Gram-negative by procedure 2 (Pl. 1, fig. 5).

Extraction of the Gram-positive cell envelopes with $0 \cdot 1 \mathrm{M}$-phosphate buffer ( $\mathrm{pH} 8$ ) caused the Gram-positive material to concentrate in the centre of the envelopes ( $\mathrm{Pl}$. 1, fig. 6); $\mathrm{M}$-sodium chloride solution had the same effect.

Numerous attempts were made to 'replate' the Gram-negative envelopes with the material extracted at pH 8 and with various other substances such as $\gamma$-globulin, ovalbumin, yeast ribonucleic acid, calf thymus deoxyribonucleic acid, and extracts from distintegrated Gram-negative organisms. When the Gram-negative envelopes were suspended in high concentrations of these 
substances and films made directly, Gram-positive staining material was observed in most cases, but, as the staining property was always lost upon washing the envelopes with distilled water, it was considered that the effect was non-specific and due to the thick films which were obtained by this procedure.

\section{DISCUSSION}

The present results render untenable, in the cases of yeast and Clostridium welchii, the simple hypothesis that the Gram-positive staining reaction is due to the inability of the dye + iodine complex to diffuse through the cell membranes. If this were the case, it is not apparent why the broken cells should stain Gram-negative by procedure 1 but Gram-positive by procedure 2 . It was also shown that methyl violet could penetrate the yeast cell membranes when heat-fixed yeast was treated with a saturated solution of the methyl violet + iodine complex in $90 \%$ ethanol. A direct proof of the permeability of the cell membranes to the methyl violet + iodine complex was not possible by these techniques because of the low solubility of the complex in ethanol. The alternative theory that the decolorizing agent cannot penetrate the cell membranes also does not explain the Gram-positive staining of broken cells by procedure 2 , since in this the decolorizing agent could easily penetrate the large gap in the yeast envelopes.

It appears that in yeast and Clostridium welchii there is a component which forms a complex with methyl violet and iodine which when dried is not dissociated by $90 \%$ ethanol, but is dissociated by $90 \%$ ethanol when the complex has not dried. It seems that drying the complex forms additional bonds between the dye and the cell component thus rendering the dissociation of the complex more difficult, or that the effect is due to the water on the slide diluting the decolorizing agent. The fact that decolorizing the dried films with $70 \%$ ethanol gave mainly Gram-negative staining supports the latter explanation, although drying the films did fix a little of the methyl violet so that it was not removed even by $70 \%$ ethanol. As films of disintegrated Gram-negative organisms did not stain Gram-positive by procedure 2 it appears that this staining reaction was confined to Gram-positive organisms and indicated the presence of a specific Gram-positive component in yeast and Clostridium relchii. The fact that procedure 2 gave a typical staining reaction with a series of intact Gram-positive and Gram-negative organisms is additional evidence in favour of this conclusion. The normal Gram-positive reaction of intact yeast cells, i.e. with a wet slide and $90 \%$ ethanol as the decolorizing agent, may be due either to increased stability of the Gram-positive complex in an intact cell as compared with a broken cell, or to some selection by the cell membranes of the concentration of ethanol which penetrates the cell. That is to say, the Gram reaction in yeast and in $C$. welchii can be attributed in part to a specific cell component and in part to an orientation or membrane effect. The chemical nature of the component in disintegrated yeast which stains Gram-positive by procedure 2 is under investigation.

The authors thank Professor M. Stacey, F.R.S., for his interest in this work. 
Journal of General Microbiology, Vol. 21, No. 3
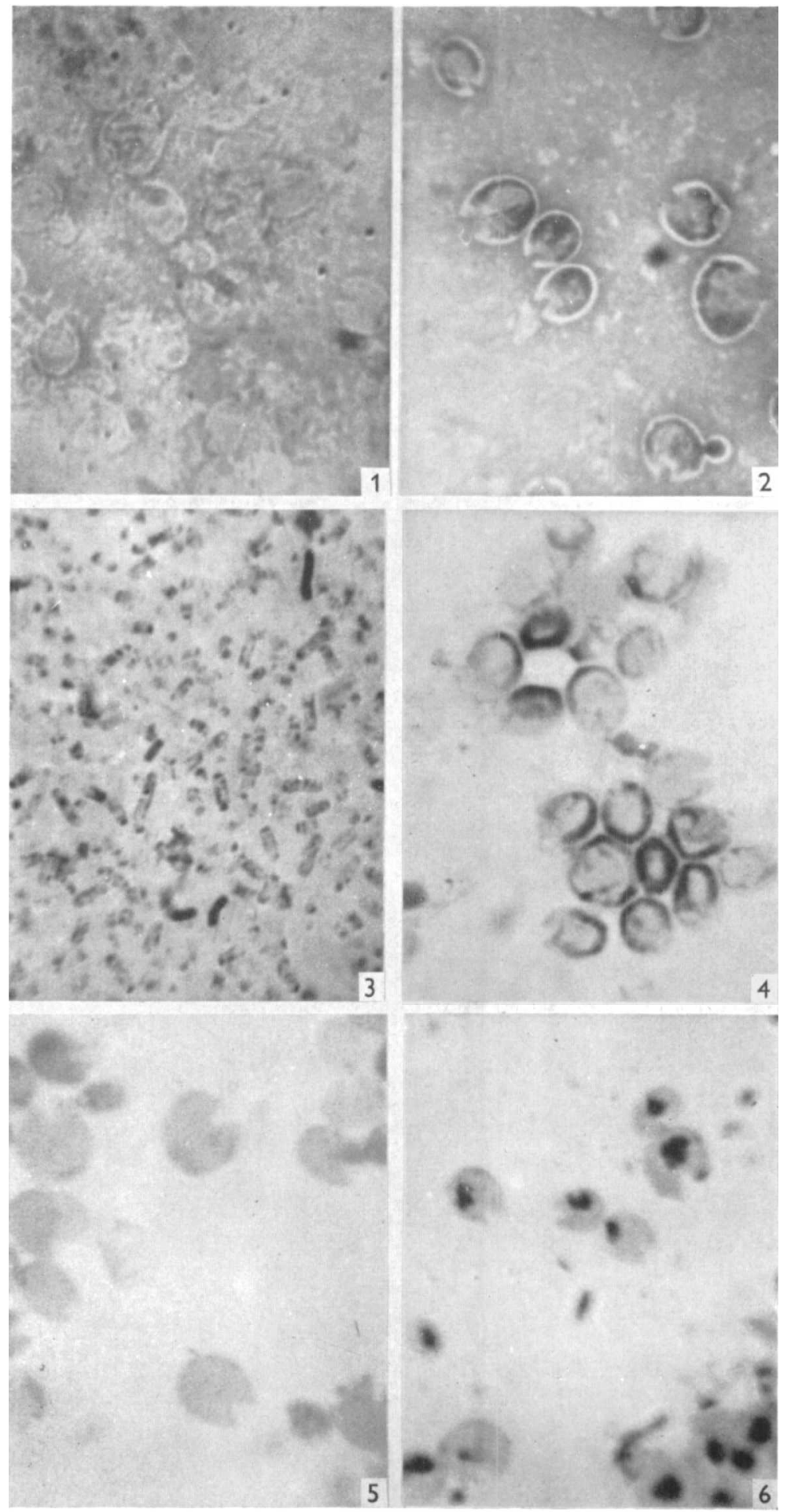

E. 'T. J. Chelton \& A. S. Jones-Gram staining of disintegrated organisms. Plate 1 


\section{REFERENCES}

Benians, T. H. C. (1912-13). Observations on the Gram-positive and acid-fast properties of bacteria. J. Path. Bact. 17, 199.

Benians, T. H. C. (1919-20). A further investigation into the principles underlying Gram's stain with special reference to the bacterial cell membrane. J. Path. Bact. 23, 401.

Burke, V.(1922). Notes on the Gram stain with a description of a new method. $J$. Bact. 7, 159.

Burke, V. \& Barnes, M. W. (1929). The cell wall and the Gram reaction. J. Bact. $18,69$.

Hucker, G. J. (1922). Comparison of various methods of Gram staining. Abstr. Bact. 6, 2.

Hucker, G. J. \& ConN, H. J. (1923). Methods of Gram staining. Tech. Bull. N.Y. Agric. Exp. Sta. no. 93.

KEMP, H. A. (1931). Gram reaction in crushed yeasts. Stain Tech. 6, no. 253.

Mickle, H. (1948). Tissue disintegrator. J. roy. micr. Soc. 68, 10.

\section{EXPLANATION OF PLATE}

Fig. 1. Film of disintegrated yeast stained by Gram's method, procedure 1 (see text). $\times 1800$.

Fig. 2. Film of disintegrated yeast stained by Gram's method, procedure 2 (see text). $\times 1200$.

Fig. 3. Film of disintegrated Clostridium roelchii stained by Gram's method, procedure 2. $\times 1800$.

Fig. 4. Gram-positive envelopes obtained by washing disintegrated yeast with distilled water. Stained by procedure $2 . \times 2200$.

Fig. 5. Gram-negative envelopes obtained by washing Gram-positive yeast envelopes with dilute sodium hydroxide $(\mathrm{pH} 8)$. Stained by procedure $2 . \times 2400$.

Fig. 6. Gram-positive yeast envelopes treated with 0.1 M-phosphate buffer (pH 8). Stained by procedure $2 . \times 1800$. 